\title{
Transitive Poetry: Arts-Based Research as a Mode for Student Voice
}

\author{
Tonya D. Callaghan \\ University of Calgary \\ tdacalla@ucalgary.ca \\ Zachary W. Wierzbicki \\ University of Calgary \\ Hannah Chevrette-McIvor \\ University of Calgary
}

\begin{abstract}
Arts-based research marks a unique nexus of curricula and its social context. Through the application of semiotics and a focus on anti-oppressive pedagogy, this paper articulates the function of art curricula in empowering student voice to approach and begin to dismantle the oppression of minoritized peoples. We have initiated a political, participatory application of Erasure Poetry that emphasizes the relationship of participants to their broader political environment. The presence of students throughout every dimension of the classroom experience makes the facilitation of their voices a key tool for consciousness-raising and the promotion of equitable, pluralistic, and democratic pedagogies. We posit that making political poetry is an important vehicle for personal reflection, critical thinking, self-expression, and demonstrating knowledge through action that is particularly effective for engaging minority learners, such as those who identify as gender and sexually diverse, in conservative times.
\end{abstract}

Keywords: Erasure poetry, semiotics, student voice, gender \& sexually diverse learners

The application of arts across various curricula in order to represent social meaning is a field of pedagogy that embodies Paulo Freire's vision for a student-centered system of education (Freire, 1970). From May to August 2016, a member of our research team participated in a Prairie University's Program for Undergraduate Research Experience (PURE), investigating discursive patterns in media accounts detailing the implementation of supportive initiatives for Lesbian, Gay, Bisexual, Transgender, and Intersex (LGBTI) students. This research topic emerged, in part, from our team member's ongoing efforts to support LGBTI youth and young adults through their volunteer work leading the Student LGBTI Club at the university. As an organization, the Student LGBTI Club collaborates with organizations in the broader LGBTI community to engage LGBTI and allied students. This PURE project closely connected to the principal investigator's international comparative study about homophobia and transphobia in Catholic schools across Canada, the United Kingdom, Australia, and New Zealand. The PURE study was a critical discourse analysis of media accounts pertaining to the implementation of progressive guidelines for LGBTI students in Catholic schools. It involved several stakeholders including parents, religious leaders, teachers, administrators, public health officials, and the students themselves. The objective of this research was to characterize stakeholder voices in 
order to establish an understanding of the patterns of conflict that impede the advancement of LGBTI rights within the institution of education. Comparing Commonwealth countries served to emphasize that these narratives were not isolated and disconnected, but followed from higher order discourses that maintain hegemonic hierarchies of power to the detriment of minoritized peoples. The reported events shared several common themes whereby "the construction of news is most of all a reconstruction of available discourses" (van Dijk, 1983, p. 29), which provides insight into not only the event itself, but also the "qualitative data with which to map the trends in public (dis)approval" of a particular topic (Herriot, 2011, p. 215). Overall, the news reports reinforced the hegemonic order, and public responses to the news events in various forms of commentary on social media continued to circulate oppressive dominant ideology in a cycle that is difficult to break and endlessly harmful to minoritized groups.

The PURE study was conducted with the mentorship and supervision of the principal investigator and was part of a larger study called The Catholic Closet. This was a multiphase, cross-case analysis of Catholic schools in the aforementioned Commonwealth countries exploring the depth of discrimination experienced by LGBTI students and staff. The Catholic Closet employs Critical Discourse Analysis (CDA) as a method for uncovering the complex discourses present within the various documents (Fairclough, 1998; van Dijk, 1997). The process of CDA requires linking close readings of texts to larger themes of power and social inequality, which is a fitting method for asking probing questions about representation, resistance, and power. As part of The Catholic Closet research activities, the PURE award winner supported an Erasure Poetry ${ }^{1}$ workshop for the Calgary Young Writers Conference, an initiative that connects students with professional writers and storytellers who share their craft and inspire students to pursue literacy-based interests. Erasure poetry (discussed more fully in a later section), challenges the poet to discern their own discourse within the text and enact their voice through creative manipulation of the source material. After witnessing first-hand the success of this workshop, the research assistant was able to envision a greater political potential for this art form in its ability to manipulate language to create or recreate meaning and discourse through the interplay of the original text with the poet's embodied positionality. Specifically, the researcher was interested in the CDA potential of the Erasure Poem to stand as the meeting ground between text and body; being both spoken for and speaking, acted upon and acting.

Working within a research team to investigate an emerging body of evidence that documents the clash between the rights of LGBTI students and religious freedoms in Catholic schools (Callaghan, 2018; Covert, 1993; Varnham \& Evers, 2009), the research assistant developed a variation of the Erasure Poetry workshop that was designed for the Calgary Young Writers Conference workshop, but this time for a much different audience: Camp fYreflyCalgary. Originating at the University of Alberta, Camp fYrefly is a summer camp designed to support and foster resiliency and leadership skills among LGBTI youth in their local communities. Part of this mandate is the provision of workshops organized and offered by community members, though varying greatly in content, with a focus on fostering resiliency, leadership, and wellness broadly. Art is a recurring motif for empowering students in these workshops, as each year the camp retains an artist in residence. We submitted a proposal for our workshop and were allotted a single ninety-minute period to work with the campers. All workshops were advertised far in advance with registration being fully voluntary. We had ten

\footnotetext{
${ }^{1}$ Originally called a "black-out" poetry workshop, its name was later changed to "erasure poetry," which is another less racially charged way of referring to this style of creating poetry.
}

Cultural and Pedagogical Inquiry, Summer 2018, 10(1), pp. 90-102

ISSN 1916-3460 (C) 2018 University of Alberta

http://ejournals.library.ualberta.ca/index.php/cpi/index 
registrants ranging from fourteen to eighteen years of age along with two "Youth Leaders," campers over the age of eighteen tasked with mentoring and supporting their peers while also participating in camp activities. Working with the registrants, the researcher initiated the session by outlining the activity and establishing community expectations around student interactions during this workshop. Students were able to decide if they wished to work collaboratively or independently on their projects with the expectation that they would ask for consent prior to viewing each other's work. Everyone elected to work on their own poems, but they discussed the process actively throughout the session. Two limiting factors of the experience were that most students did not complete their poems within the period and the research team did not secure university ethical clearance to engage the students after or outside of the camp.

By critically analyzing media accounts detailing the influence of LGBTI youth narratives and experiences with homophobia and transphobia in school settings, the workshop facilitated a political, participatory application of Erasure Poetry that emphasized the relationship of the participants to their broader political environment. Drawing upon CDA, the researcher led the participants in undertaking close readings of the media accounts and linking them to larger struggles over power and social inequality associated with one news phenomenon in particular, the passage of Bill 10 in Alberta in 2014. Through this exercise, the participants created poems that embodied the relationship between their lived experiences and the political discourses of media accounts associated with Bill 10.

In Canada, education is broadly defined, regulated, and enshrined within individual provincial law insofar that changes in legislation do not carry over to other provinces (Guven \& Gurdal, 2011). Specifically, Bill 10 was an amendment proposed by the Alberta Provincial Legislature to the Alberta Bill of Rights to Protect our Children, which recognizes fundamental human rights, including the right to individual liberty, the right of the individual to equality before the law, freedom of religion, freedom of speech, and freedom of assembly (Jansen, 2014). The Bill 10 amendment that we are most concerned with falls under the anti-bullying and nondiscrimination section, which states that staff members employed by a school board must support students in their endeavours to "establish or lead an activity or organization intended to promote a welcoming, caring, respectful and safe learning environment that respects diversity and fosters a sense of belonging" (Jansen, 2014, p. 2). Though education is independently legislated within each province, reflecting a greater social trend in the advancement of LGBTI youth, other provinces have also implemented similar legislation such as Bill 13, the Accepting Schools Act, in Ontario (Broten, 2012) and amendments to the British Columbia (BC) Human Rights Code protecting citizens, including students, from discrimination against their gender and sexual identity (Government of BC, 2016).

The media accounts surrounding the passage of Bill 10 painted one portrait of life in schools for LGBTI students, but we found that portrait to be incomplete and not reflective of the radically different lived experiences of diverse LGBTI youth. Similar to Bill 13 in Ontario, an act that amends Ontario's Education Act with respect to bullying, citing the importance of creating safe learning environments for students (Broten, 2012), Bill 10 amended provincial legislation to mandate the formation of Gay-Straight Alliances (GSAs) in any of the schools where students had requested them. This legislation, and the later associated Guidelines for Best Practices: Creating Learning Environments that Respect Diverse Sexual Orientations, Gender Identities and Gender Expressions, hereafter Guidelines, (Alberta Government, 2016) garnered considerable support as well as animosity in the public sphere. Prior to Bill 10 coming into force, 
the legislation underwent significant revisions. The provision allowing school boards to reject the formation of a GSA, stipulating that such a rejection could only be challenged by students in court, was crucially removed from the legislation. The Premier of Alberta at the time, Jim Prentice, attributed the change in legislation to the power of the media accounts in bringing the voices of Alberta youth to the debate (CBC News, 2015).

\section{Erasure Poetry}

Erasure Poetry is a specific style and method of poetry writing that challenges the poet to write a poem through the erasure of words from a pre-existing text without altering the sequence or adding any additional words, while allowing for adjustments in punctuation or tense. The selected words, those that have not been erased, are then compiled so that they may be paired, by whatever means the creator wishes, with the original text. While certainly embodying a distinct challenge in its construction, this form of poetry focuses the writing process on the selection of words from an established lexicon rather than assuming or exclusively relying upon the particular linguistic resources of the students. Depending on the pedagogical needs of the classroom, this style of poetry could be adapted to a wide range of needs and contexts through adjustments, such as allowing students to select their own personally-relevant source text, providing opportunities for English Language Learners to engage texts in their primary languages, or the careful provision of texts originating from minoritized voices.

The strength herein lies in the tangible starting point for engaging a subject through the restructuring of extant public discourses, the ubiquity of these discourses across subject matters, and the independence of the writer to build upon or deconstruct the intention of the original text as a political act. With finesse, this technique allows students to creatively craft a message by looking at the strategic elimination or delocalization of a negative within the text, or selectively eliminating voices from an article. In this way, the relationship between final product and the source also serves as a vehicle for creating meaning and voice. As a hypothetical example, a writer concerned with women's reproductive rights might select an article that favours men's voices on the subject and preserve only the text attributed to women. Juxtaposing the original text against the final product, the combined piece can highlight the problematic privileging of specific identities. Politically, this process is expansive as the poet is free to select texts based on the content, the author, the medium, mode of distribution to the public, or any number of other contributing political characteristics.

For the purposes of the Erasure Poetry workshop, participants were presented with a selection of news articles containing a variety of supportive and oppositional perspectives on the passage and purposes of Bill 10. These media accounts included news articles, opinion columns, and blog posts. We employed several provisions to support youth and acknowledged the possible traumas associated with these discourses such as explicitly inviting participants to either step away or change texts at any juncture where they felt overwhelmed, reminding them of the peer support networks in place at the camp, detailing and organizing the texts based on their potential to trigger trauma, and discussing this informal "scale" with them prior to selection. Participants then got to work reading and digesting the information contained within the articles in preparation for the creation of poetry. Reading over their articles, participants selected the words to be removed in addition to the words that would be retained in the original text. Without altering the sequence of their chosen article, the words that were not crossed out eventually formed the bulk of the Erasure Poem. Considering composition and form, students transcribed 
their poems, created from the words they chose to keep, onto a transparency that would then be overlaid onto the original text. While the original text remains whole and legible underneath the overlaid poem, the intention and interpretation are transformed by the superimposed transparency.

To then facilitate an authentic reading of their poems by external parties, the participants also wrote an accompanying explanation of the contexts and semiotics that informed their project - adding a more human and exploratory dimension to their work. Their final artifact, left to the discretion of the participant, was to then be sent to their respective Members of the Legislative Assembly (MLA) to engage provincial politicians in consciousness-raising as it relates to the implications of social and political discourses in the lives of LGBTI youth. The participants' experiences encompassed the collective interpretation of the media accounts, the creation of the poetry, and the transformation of the poetry into a stand-alone artifact. Participants were free to send their poems to their own MLA (MLAs represent specific ridings or areas within Alberta), or to other MLAs based on relevance such as the representative's position, citation within the article itself, or public position on the issue. In this way, the Erasure Poetry experience invited each participant to take part in political activism. The research assistant conducting the Erasure Poetry workshop for the young Camp fYrefly campers noted an observable change in the demeanor of the campers as they worked through the various stages of the workshop. As participants moved from trying to make sense of the media accounts to blocking out the words that impeded their understanding of the stories, they seemed to take pride in the creation of their poems, helping the participants to personalize the meaning of Bill 10 and its impact on their lives. This being our primary goal with the workshop, to impart a skillset for LGBTI youth to tangibly engage with political discourse and initiate conversations around political action rooted firmly in the arts.

\section{Theoretical Framework}

We propose that the participants' creation of this form of poetry is a complex negotiation of positionality, within the domain of critical pedagogy and anti-oppressive research in education (Giroux, 2001). The application of imagery encoded through various literacies in art recalls an aspect of semiotics involving "the study not only of what we refer to as 'signs' in everyday speech, but of anything which 'stands for' something else" (Chandler, 2002, p. 2). In a semiotic sense, the selection and omission of words necessitates decoding and re-encoding the meaning of the text, which may include "words, images, sounds, gestures and objects" (Chandler, 2002, p. 2) to create new meaning and alter relationships to the greater discourse of these signs or symbols. Because the "personal" is nested within the specific histories of the individual, the construction of meaning through art, which is itself an extension of semiotics, offers a unique point of entry for the experiences of identities not normally discussed in classroom settings. While this research focuses primarily on the LGBTI identities that do not receive attention in mainstream school curricula, we acknowledge that these identities intersect with students' experiences with race and ethnicity, language, socio-economic standing, religion, ability, and a myriad of other identities that fall outside of the dominant culture. As a linguistic anthropologist, Heller addresses the historical and ongoing exclusion of marginalized groups in schools by looking at how teachers facilitate students in the creation of personal, holistic meaning related to external concepts and posits that this allows for the revaluing of "the semiotic resources of non-dominant communities in school settings" (as cited in Smythe \& Neufeld, 2010, p. 490). Ideally, the facilitator of the Erasure Poetry activity not only takes into consideration the fact that each participant is party to a 
number of intersections of identity, but also actively targets these diverse, embodied elements. By creating a space for participants to represent and explore their personal subject position, facilitators establish a value for pluralism without drawing undo attention to diverse communities. Given that the Erasure Poetry the participants create originates with the community members themselves rather than being externally introduced, the act of creating the poem and the product itself is wholly authentic without treading into stereotype or cliché. The participants consent to every action and every word.

This application of art and semiotics recalls Paulo Freire's (1970) banking concept of education, which is a critique of the way traditional education systems regard students as empty vessels into which educators deposit knowledge: "Apart from inquiry, apart from the praxis, individuals cannot be truly human. Knowledge emerges only through invention and re-invention, through the restless impatient, continuing, hopeful inquiry human beings pursue in the world, with the world, and each other" (1970, p. 72). In light of Freire's critical pedagogy and Heller's semiotic lens, we regard the process of acquiring knowledge as a cyclical exchange between the learner and the external world through a praxis of defining and redefining those interactions within their personal contexts. The opportunity to redress the tendency of schools to devalue the cultural, linguistic, and popular culture resources of low-income, new-comer, and Englishlanguage learners occurs when students and teachers exchange ideas and experiences (Gonzalez, Moll, \& Amanti, 2005). Rather than learning through one person's lens, typically that of the educator, the scope is broadened to better capture students' diverse experiences. This expanded perspective revalues the reality of marginalized students, creating anti-oppressive, nondiscriminatory learning environments that allow many voices to speak and be heard.

These critical perspectives inform an artistic process that seeks to substantiate and actualize the importance of students' cultural, personal, and pedagogical resources within their learning environments towards challenging the long histories of schools rejecting the minoritized identities, and in imagining new, inclusive learning environments. These elements informed the Erasure Poetry workshop at Camp fYrefly, thereby indicating an arts-based research approach as the primary theoretical framework for this exercise. McNiff defines art-based research as: "the systematic use of the artistic process, the actual making of artistic expressions in all of the different forms of the arts, as a primary way of understanding and examining experience by both researchers and the people that they involve" (2008, p. 29).

The artistic process becomes an act of constantly revisiting the creation of knowledge as it relates to power. The "actual making of artistic expression" is itself a re-invention of knowledge that disorganizes an established order. Within this paradigm, the arts are the method by which the concepts of semiotics, critical, and anti-oppressive pedagogies are discerned and evaluated within a relational context in which each participant arrives at a final product unique to their positionality. As participants strive to create their Erasure poems, through the composition of words and juxtaposition of discourses, they actively engage with the matter and process of semiotics - the "meaning-making and representation in many forms" such as "texts and media" (Chandler, 2002, p. 2). Further, Finley offers that arts-based research is unique in its capacity for "radical, ethical, and revolutionary research that is futuristic, socially responsible, and useful in addressing social inequities" (2008, p. 71). By focusing on topics of utmost concern to the participants the "potential to facilitate critical race, indigenous, queer, feminist, and border theories" (Finley, 2008, p. 71) is enabled. Instead of researchers imposing their gaze on issues of social significance, participants' authentic voices emerge through their involvement in arts-based 
research. Furthermore, our understanding grows through the "invention and re-invention" of knowledge (Friere, 1970).

\section{Student Voice and Identity}

A Gay-Straight Alliance (GSA) is an in-school club that embodies time set aside and a place to go, a meeting where young people who identify as LGBTI and their allies can come together for simple friendship and support. The focus and function of a GSA can vary from school to school. Sometimes the GSA meeting is just about eating pizza while watching a movie together and discussing it later. Other times, the activities the members get involved with are more political in nature; for example, organizing how to take part in the local Pride parade. The GSA can also be an important place for personal expression; that is, a space taken up within the school where the often-private matters of sexuality, attraction, the very body itself, the transgressive act of owning and of being a body, are given leave to take up public space. Instead of being spoken for, written upon, bestowed an identity that does not fit, the body speaks for itself, writes for itself, creates itself. As such, the absence or inconsistent regard for the voices of LGBTI youth in crafting the public policy regulating GSAs embodied a discursive characteristic we intended to redress through political, artistic mobilization.

Creating GSAs in schools is an act of anti-oppressive pedagogy and inclusive education that embraces and empowers student identities so that students might be educated within an environment that respects the plurality of diversity. Without anti-discriminatory clubs like GSAs, gender and sexually diverse students are expected to exist privately, or actively hide aspects of themselves, in schools. Existing privately for LGBTI students often involves feeling as though they have to shy away from public displays of affection with their partners or that they cannot discuss their romantic lives openly. In contrast, their heterosexual peers rarely have to give such negotiations much thought. Planning a night out, straight couples need not consider whether their presence will be accepted, whereas LGBTI couples must constantly evaluate for considerations of safety when making aspects of their gender and sexual diversity visible in public, unpredictable settings. Reviewing some of the many news articles describing the passage of Bill 10 in Alberta, and even scrolling through the comments, a resounding sentiment that seems to come up repeatedly is one of moralistic ambivalence, as in: "I don't care what you do in private, but why does it have to be publicized around schools?" "I don't care if you're gay, I just don't want to see it" (CBC News, 2015). These are sentiments that express a profound misunderstanding, even antipathy, for the particulars of identity: as if it is acceptable to ask only those students party to non-dominant identities to forge separate selves for their public and private lives. The subtext of such online comments is the notion that the body can be cleaved from the space it occupies, split in two and partially hidden without causing harm to the self.

Taking this exclusionary narrative into a site of resistance becomes an act of resistance. Transporting the original news articles from their normal circulation within the hegemonic order, where they are to be consumed by a public unaware of the potential harm to minoritized identities, to the entirely different site of Camp fYrefly, a camp that fosters resiliency and leadership in LGBTI youth, has the effect of dramatically changing the power dynamics. The concentration of power in the hands of a few is made unstable when moved to a diverse community where many are afforded the right to speak in a democratic manner. The object therein acts upon the subject. As marginal voices who do not have space to speak their own truth, and who are often spoken for by those in the dominant culture, are now afforded the opportunity 
through the Erasure Poetry exercise to write over top of the dominant ideology. In this way, the act of writing for oneself legitimizes the lived experience that was previously negated and provides the opportunity to engage youth in developing their political voices.

To facilitate this transgressive re-scripting of narratives, the researchers brought news articles to Camp fYrefly for the purpose of understanding the positionality of diverse individuals and, with this understanding, to broker an act of healing through the creation of Erasure Poetry. This embodies an arts-based research approach. Arts-based research is process-based research that seeks to understand individuals through the creation of an artifact, material or embodied, rather than capturing experiences through traditional forms of qualitative research (Bagely \& Castro-Salazar, 2012, p. 239). By focusing on the individual identity and experiences of the person creating the poem - that is, the act of creation rather than the object being created - along with the impact of the art-making upon the individual's subjectivity, arts-based research accesses "experiential and sensuous knowledge and (helps) to co-recover and interrogate a shared memory and history while simultaneously enriching a social critique of the dominant social order" (Bagely \& Castro-Salazar, 2012, p. 242). The simple identity and finding artistic ways to re-inscribe it over top of dominant narratives highlights the compositional pieces of discrimination and oppression that contribute to a discursive hegemony in the disguise of politicking. By disrupting social order, the arbitrariness of that order is exposed. The way to be, the space to take, the voice to use - these constructs hold less power when their original form is weakened through the artistic use of Erasure Poetry.

As LGBTI students sit with the words that were written for them, words that were in many ways written overtop of them, words that instruct these students to hide their experience and conceal their reality, words that commit casual violence as they cut these students down, many questions arise: What becomes of their voice? Do they lose the power to speak against the common narrative? What action is necessary to coalesce that scattered speech into a voice of tangible and validated import? We propose that the construction of Erasure Poetry is perhaps one such act. It is an act of decoding what appears to be nonsense and then re-encoding it with the intent to reestablish personal sense or meaning. The act of creating through destruction, destroying the original text to create a text with tangible meaning, one that seeks to redefine the heart of the matter, reclaims student voice and ruptures the older senses of meaning. The old and tired sense, a construct of accepted and common reality, that conceals its assumptions and preconditions within a narrative of tradition is contrasted defiantly against the Erasure Poem that has been created from the original text's very syntax in a manner that recalls the ideas of feminist social activist bell hooks: "Moving from silence into speech is for the oppressed ... a gesture of defiance that heals.... It is that act of speech, of 'talking back' ... that is the expression of moving from object to subject, that is the liberated voice" (Hooks, 1986, p. 128). The simple act of composing an Erasure Poem challenges the notion of the singular voice and inscribes an individual's identity, literally, over the old narrative. This act of creative writing "alerts us to assumptions that are exclusionary and calls us to interrogate what we take for granted along with the current allotment of subjectivity" (Barney \& Kalin, 2014, p. 597).

\section{Anti-Oppression}

"Talking back," as hooks (1986) describes, is an act of reclaiming voice and story for the oppressed and challenging the ways we make sense of the world. Art challenges the societal distribution of power when considering who is included and excluded, who is subject and who is 
object, and it forces us to interrogate the assumptions and constructions of power (Barney \& Kalin, 2014, p. 597). As public interests and concerns with the implications and intent of Bill 10 were being circulated widely in the media, social hegemonies defining the value of sexual and gender identities were focused upon the institution of education in Alberta - entrenching themselves along political, discursive lines. Replaying these hegemonies, the general public seemed to view students, particularly LGBTI students, as objects to be signified upon. The experience of LGBTI students and the importance of forming GSAs in schools was often erased by politicians who could not understand the value of GSAs, reframing the issue around concerns for parental autonomy, religious tradition, and fears of what they regarded to be "radical activism" on the part of anti-oppression educators and students. That opposition was the loudest voice, the most powerful voice, anointing itself as the singular voice of reason and experience. Instead of centering the discussion on the experiences of those who live their lives in school, who walk through the hallways as LGBTI students, these students were made to become spectators, made witness to the manipulations of their story to serve political ends in the service of those who would prefer to deny subjectivity to certain groups. As the powerful debate the question amongst themselves, the spectator, the student is separated from both their ability to know their own story and the power to act against the story that is being told. The power dynamic becomes one where there are those who can voice their ideas openly, and those who are not afforded that privilege (Lewis, 2013, p. 63). By inscribing themselves over top of insensitive news articles, students are no longer spectators nor are they objects. Writing themselves overtop of these stories reclaims their subjectivity and therefore their power. The act of writing, writing back, is an act of taking back the self and taking back one's story.

To transgress is to infringe, to push against boundaries. Transgressing involves crossing into space that defines itself against its orbiting bodies. The transgressive body is, then, a marginalized body. When the marginalized body knocks against borders, demands admittance, speaks up and for itself, the marginalized body transgresses. When this body notices, sees what it has been told to un-see, the boundaries become permeable and arbitrary. The "sense" that was before imposed upon the marginalized body, those signs and symbols that denoted a particular existence of alienation, are no longer fixed and immutable. From this exercise in the construction of meaning, a new reading can be uttered. A new order can be enacted. As postcolonial theorist, Homi Bhabha (1994) noted regarding the interstices of language and culture, these borderlands "ensure that the meaning and symbols of culture have no primordial unity or fixity; that even the same signs can be appropriated, translated, rehistoricized and read anew" (p. 55). After the act of creating Erasure Poetry, the artifact stands as a new reading that translates the signs and symbols of an old order into the signs and symbols of resistance. Language can be spoken anew, overwritten and translated into the language and writing of anti-oppression. Those who could not think or speak cross that border between object and subject, a transitive linguistic shift, to claim thought and voice.

An Erasure Poem ultimately looks like words floating through disjointed space. There is the legible space, the words standing out and calling attention to themselves in contrast to the null space, the illegible, ambiguous, demarcated words. The illegible, non-speaking spaces, have been enacted upon and this action, this creation of space, makes room for new forms of speech. The in-between unfixes the cohesive, comprehensive narratives that the news articles appear to tell and creates new comprehension out of disorder made manifest from words previously unjoined. Out of the many subject positions that students hold, out of their many identities and experiences, this new comprehension emerges. The action of the individual, the story of the Cultural and Pedagogical Inquiry, Summer 2018, 10(1), pp. 90-102 
individual, disentangles the consensus so that many voices, that crushed-in amalgam of otherness, is invited to speak, decompressed. This erodes the power of any singular politician or researcher's position to highlight the collective nature of research that functions, not with a single consensus, but with multiple perspectives and positionalities (Barney \& Kalin, 2014). The one no longer stands for the whole with arts-based research.

The act of disrupting consensus with Erasure Poetry is subversive because it asks collections of people to engage with texts and harmful narratives; but beyond subversion, it is also a playful act. It is a chance to play with identity and positionality, the particulars for the thoughtful erosion of prescribed identities affords access to a variety of avenues as broad as art itself. It is a chance to decode and recode language to represent the self in its diversity. Playing with Erasure Poetry is a personal act that has students engage with the text in a way that feels authentic. This kind of engagement does not ask students to come to one meaning, but to understand the self as it may play itself out across a medium or narrative. Students are asked to engage simply to create sense for themselves. Quoting Ranciere (2008), Lewis (2013) explains that "literature emancipates when it doesn't tell us how to use art or literature - how we have to understand, how we have to see, how we have to read, and what we have to understand" (p. 64). This playful emancipation that engages with boundaries, borderlands, and in-between spaces breaks the opposition between the object and the subject, the seen and the unseen, the learner and the teacher, the powerful and the marginal, to be able to shift boundaries and walk across them (Lewis, 2013). This ambiguity that is neither here nor there, in nor out, breaks down the symbols that are placed over top of oppressed bodies and diminishes the power to use those symbols to oppress. The favoured term loses some of its luster and the opposition loses some of its tension until the dichotomies and hybridities that people embody can exist in one body. Through the act of creating an Erasure Poem, the marginalized LGBTI youths experience a state in which they are no longer halved and set aside, but whole and fully present.

\section{Educational Importance}

The student body, used here to refer to the entirety of those individuals enrolled within publicly regulated educational settings, represents a tremendous spectrum of diversity. Where some students' effective access to education is obstructed by homophobic and transphobic policies and school cultures, educators have an obligation to pursue practices that empower and create opportunities for non-dominant identities to access and be recognized within educational settings. Although educators might aspire to be completely cognizant of learners' lived experience within education and believe that they can speak to these realities, it is ultimately students who occupy the gaps and have the greatest opportunity for consciousness-raising.

In 2015, Bill 10 was introduced to support LGBTI students in Alberta. The early forms of the Bill featured a stipulation that a school board could refuse the formation of a GSA, requiring students to take their school board to court in order to overturn their board's decision. This section was later removed, with the Premier citing the responses of students and young people impacted by the highly public debate (CBC News, 2015). The Premier's reaction to student voice demonstrates that the transgressive elevation of the lived experiences of minoritized students holds the potential to realize emancipatory change. The strength of speaking out and holding politicians to account is in its appeal to empathy: LGBTI identities were empowered by the capacity of their lived experiences to incite and compel the political class to take ameliorative action. Even when considering the possibility that the eventual political momentum of this Bill 
may not have originated entirely with a profound concern or understanding of LGBTI identities, the result, and particularly the result as framed by those who originally opposed the final amendments, reveals a construction of events that appealed to those in power - that empathy should inspire change.

The emphasis on a multidisciplinary model, which includes an arts component, promises that school communities can create avenues for diverse identities to enter the classroom in a fashion that empowers student positionality (Friere, 1970; Heller, 2008; Gonzalez, Moll, \& Amanti, 2005; Finley, 2008; McNiff, 2008; Smythe \& Neufeld, 2010; Bagley \& Castro-Salazar, 2012; Barney \& Kalin, 2014). As such, the creation of Erasure Poetry allows students to reflect on how their personal experiences can both inform their own expression, and can affect change in a larger arena. The layering of texts creates pedagogical space that not only affords students the opportunity to draw upon the full range of their semiotic resources, those personal informational or textual resources that comprise their positionality, but to employ these resources creatively and critically as students navigate and negotiate the discursive positions embodied within their classroom, political environment, and their own subjectivity (Smythe \& Neufeld, 2010). This makes tangible the students' knowledge and understanding of these constructs through the creation of an accountable, auditable artifact. The application of the visual arts has clear implications for realizing political change, as the creation of art out of political discourse nests and elevates student subjectivity, agency, and voice within those public discourses that directly impact student life.

Through initiatives such as GSAs and curriculum practices that respect and provide opportunities to utilize and value the semiotic resources of minoritized identities, we erode the monolithic legacies of oppression nested within our educational settings. Nonetheless, efforts to support the diversity of the student body will ultimately depend upon educators and administrators. These educators themselves may embody a certain spectrum of diversity; however, initiatives designed to redress discrimination and marginalization will at times be enacted by educators who may have limited experience with various forms of diversity. Thus, the focus of Erasure Poetry, in this context, was not to gather students and task them with generating pro-GSA poems, but to entirely decentralize the learning experience so that the students' poems could develop from their specific subjectivities. Even in instances where students may harbor negative or discriminatory conceptualizations of identities, their own or those of others, this practice invites a certain level of self-reflection whereupon students may encounter contrary perspectives in a safe and accepting setting that leads them to interrogate their own assumptions. Though Erasure Poetry has many strengths which serve to realize the emancipatory nature of this work, its greatest attribute is its focus on enabling the expression of student voice through art and, as such, there is tremendous room for pedagogical invention to provide such opportunities. In an educative practice that values and emphasizes student positionality, there is more space for creative, imaginative learning that is both inclusive and non-discriminatory. The development of student voice is key to actualizing equitable, pluralistic, and democratic pedagogies and, optimistically, societies. 


\section{References}

Alberta Government. (2016). Guidelines for best practices: Creating learning environments that respect diverse sexual orientations, gender identities, and gender expressions. Retrieved from: https://education.alberta.ca/media/1626737/91383-attachment-1-guidelines-final.pdf

Bagley, C. \& Castro-Salazar, R. (2012). Critical arts-based research in education: Performing undocumented historia. British Educational Research Journal, 38(2): pp. 239-260. doi:10.1080/01411926.2010.538667

Barney, D. T. \& Kalin, N. M. (2014). The poster and the poster: Critical arts-based research as dissensual aesthetics. Cultural Studies - Critical Methodologies, 14(6): pp. 595-605. doi:10.1177/1532708614548131

Bhabha, H. K. (1994). The location of culture. New York, NY: Routledge.

Broten, L. C. (2012). Bill 13: Accepting schools act. Retrieved from: http://ontla.on.ca/web/bills/bills_detail.do?locale $=$ en\&BillID $=249$

Callaghan, T. D. (2018). Homophobia in the hallways: Heterosexism and transphobia in Canadian Catholic schools. Toronto, ON: University of Toronto Press.

CBC. (2015, March 11). Bill 10 to allow gay-straight alliances for any student in Alberta schools. Retrieved from: http://www.cbc.ca/news/canada/edmonton/bill-10-to-allow-gay-straight-alliances-forany-student-in-alberta-schools-1.2989399

Chandler, D. (2002). Semiotics: The basics. London, England: Routledge.

Creswell, J. W. (2009). Research design: Qualitative, quantitative, and mixed methods approaches $\left(3^{\text {rd }}\right.$ ed.). Thousand Oaks, CA: Sage.

Fairclough, N. (1998). Media discourse. London, England: Oxford University Press.

Finley, S. (2008). Art-based research. In J. G. Knowles \& A. L. Cole (eds.), Handbook of the arts in qualitative research (pp. 71-80). Thousand Oaks, CA: Sage.

Freire, P. (1970). Pedagogy of the Oppressed. New York: Continuum.

Giroux, H. A. (2001). Theory and resistance in education: Towards a pedagogy for the opposition. Westport, CT: Bergin \& Garvey.

Gonzalez, N., Moll, L. C., \& Amanti, C. (2005). Funds of knowledge: Theorizing practices in households, communities, and classrooms. Mahwah, NJ: Erlbaum.

Government of B.C. (1996). Human rights code. Retrieved from: http://www.bclaws.ca/EPLibraries/bclaws_new/document/ID/freeside/00_96210_01 
Guven, I., \& Gurdal, A. (2011). A comparative analysis of the education systems in Turkey and Canada: The similarity and the difference. US-China Education Review, B(4), 534-546. Retrieved from: https://eric.ed.gov/?id=ED526793

Heller, M. (2008). Bourdieu and "literacy education". In J. Albright \& A. Luke (eds.), Pierre Bourdieu and literacy education (pp. 50-67). New York: Routledge.

Hooks, B. (1986). Talking back. Discourse, 8: pp. 123-128. Retrieved from: http://search.proquest.com.ezproxy.lib.ucalgary.ca/docview/1311733653/fulltextPDF/E2 68A270476E4D88PQ/1?accountid=9838

Jansen. (2014). Bill 10: An act to amend the Alberta bill of rights to protect our children. Retrieved from: http://www.assembly.ab.ca/ISYS/LADDAR_files/docs/bills/bill/legislature_28/session_3 /20141117_bill-010.pdf

Lewis, T. E. (2013). Jacques Ranciere's aesthetic regime and democratic education. The Journal of Aesthetic Education, 47(2): pp. 49-70. Retrieved from: http://www.jstor.org/stable/10.5406/jaesteduc.47.2.0045

McNiff, S. (2008). Art-based research. In J. G. Knowles \& A. L. Cole (eds.), Handbook of the arts in qualitative research (pp. 29-40). Thousand Oaks, CA: Sage.

Ranciere, J. (2010). The Ethical turn of aesthetics and politics. In S. Corcoran (ed.), Dissensus: On politics and aesthetics (pp. 184-201). New York, NY: Continuum.

Smythe, S. \& Neufeld, P. (2010). "Podcast time": Negotiating digital literacies and communities of learning in a middle years ELL classroom. Journal of Adolescent \& Adult Literacy, 53(6): pp. 488-496.

van Dijk, T. A. (1997). The study of discourse. In T.A. van Dijk (Ed.), Discourse as structures and processes (pp. 1-34). London, England: Sage. doi:10.1177/0957926597008004001

Varnham, S. \& Evers, M. (2009). Secular, singular, and self-expression? Religious freedom in Australia and New Zealand education. Irish Educational Studies, 28(3), 279-296. http://doi.org/10.1080/00344087.2014.887929 